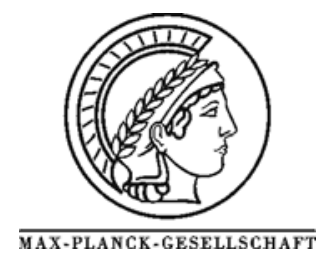

\title{
XPS investigations of VPO catalysts under reaction conditions
}

\author{
E. Kleimenov ${ }^{1 *}$, H. Bluhm ${ }^{1 \#}$, M. Hävecker ${ }^{1}$, A. Knop-Gericke ${ }^{1}$, A. Pestryakov ${ }^{1}$, D. Teschner ${ }^{1}$, \\ J.A. Lopez-Sanchez ${ }^{2}$, J.K. Bartley ${ }^{2}$, G.J. Hutchings ${ }^{2}$, R. Schlögl ${ }^{1}$ \\ ${ }^{1}$ Department of Inorganic Chemistry, Fritz-Haber-Institute of the MPG, Faradayweg 4-6, 14195 Berlin, Germany \\ ${ }^{2}$ Cardiff University, Department of Chemistry, P.O. Box 912, Cardiff, UK CF10 3TB \\ \#present address: Lawrence Berkeley National Laboratory, Chemical Sciences Division, Berkeley, CA 94720 \\ * Corresponding author: e-mail kleimen@,fhi-berlin.mpg.de, fax +49 3084134681
}

Received: 2 July 2004, accepted for publication 12 November 2004, available online 28 November 2004

\section{Abstract}

The surface of vanadium phosphorus oxide (VPO) catalysts was investigated by (in situ) X-ray photoelectron spectroscopy (XPS) under reaction conditions. Two differently prepared VPO samples with similar catalytic activities showed different spectral behavior while the catalytic conditions were changed. The vanadium surface oxidation state of both catalysts was found to have the same value close to 4 under reaction conditions, while the oxidation state of vanadium in deeper layers differed significantly. The experimental results suggest that in VPO the catalytically active species located in the topmost surface layers (up to $1 \mathrm{~nm}$ depth) are only weakly related to the structure of deeper layers. Based on our results we suggest that the deeper layers act as a substrate material only and can be different from the surface.
\end{abstract}

Keywords: X-ray photoelectron spectroscopy, catalysis, vanadium phosphorus oxide, powders, n-butane, maleic anhydride, surface chemical reaction

\section{Introduction}

For the last three decades vanadium phosphorous oxides (VPO) have been the only catalysts that were used for the industrial production of maleic anhydride (MA) from $n$ butane. These catalysts have been a subject of numerous studies since their invention. The complexity of the chemical reaction and the multiphase composition of the catalyst, however, still leave open questions about the nature of the active surface and the reaction mechanism. Different models of the active phase were presented in the literature [1-8]. Some authors suggest a $\mathrm{V}^{4+}$ phase to be catalytically active and the presence of $\mathrm{V}^{5+}$ phases to be detrimental for the catalytic performance. Others in the contrary stating the positive role of the $\mathrm{V}^{5+}$ and the negative one of the $\mathrm{V}^{4+}$ phases.

It is generally accepted that well crystallized (VO) ${ }_{2} \mathrm{P}_{2} \mathrm{O}_{7}$ (which is a $\mathrm{V}^{4+}$ phase) is the major phase that is present in an industrial VPO catalyst after long operation time. Several groups suggested that the (100) crystal plane of $(\mathrm{VO})_{2} \mathrm{P}_{2} \mathrm{O}_{7}$ is the catalytically most active VPO surface while other VPO phases are thought to be much less cata- lytically active or even detrimental for the catalytic activity of the sample $[1,2,3]$. Other investigations, however, indicate the participation of $\mathrm{V}^{5+}$ species in the form of $\mathrm{VOPO}_{4}$ phases, dispersed on the surface $\mathrm{V}^{4+} / \mathrm{V}^{5+}$ couples or surface and bulk crystalline defects in the catalytic process $[4,5,6,7]$. In Refs. [4-7] the importance of the presence of both $\mathrm{V}^{4+}$ and $\mathrm{V}^{5+}$ in active catalysts is stressed. Furthermore, Coulston et al. [8] argued about the central role of $\mathrm{V}^{5+}$ in the reaction and the responsibility of $\mathrm{V}^{4+}$ for byproduct formation. Such a wide range of opinions supported by experimental facts might well be explained by the location of the active material in the topmost (1-2 nm) surface layer, which can hardly be investigated by XRD, Raman, NMR and V K-edge XAS used in the works mentioned above. The participation of the first four layers in the gas-lattice oxygen exchange during the reaction was concluded from studies based on ${ }^{18} \mathrm{O}$ isotopic labeling experiments [9]. Recent TEM investigations showed the existence of a thin (about $1 \mathrm{~nm}$ ) amorphous layer on top of $(\mathrm{VO})_{2} \mathrm{P}_{2} \mathrm{O}_{7}$ for VPO catalysts [10]. Some other observations [7,11,12] could be viewed as indirect prove for the presence of a thin active layer on top of a bulk phase. Bulk VPO and VPO supported on $\mathrm{SiO}_{2}$ substrate were found to have equal cata- 
lytic properties[11]. The supported VPO, however, had an amorphous nature, while the bulk VPO was crystalline. Furthermore, a completely amorphous VPO catalyst was synthesized using supercritical $\mathrm{CO}_{2}$ [12]. For this catalyst no activation time was necessary to reach full catalytic performance. In addition, no crystallization of the material was observed during the reaction, which is in contradiction to modern methods of industrial catalyst preparation. Earlier observations [7] of similar intrinsic activity to MA (i.e. activity divided by the surface area) for catalysts prepared by different methods and having different bulk phase compositions also indicate that bulk and surface layers do not necessarily consist of the same phases.

The goal of our study is to investigate the relationship between catalytic activity of an VPO catalyst and its bulk and surface composition under reaction conditions. If the active layer is found to have indeed a different structure than the bulk, this could be an important finding for the improvement of the performance of VPO catalysts. While the modern preparation methods are designed to produce catalysts with a $(\mathrm{VO})_{2} \mathrm{P}_{2} \mathrm{O}_{7}$ bulk phase, it might be more important to optimize the preparation process towards the formation of an active surface layer. The long activation time of the industrial catalyst could be related to structural rearrangement and a water desorption process, which disturb the active layer. A substrate different from (VO) ${ }_{2} \mathrm{P}_{2} \mathrm{O}_{7}$ can be chosen for the active layer. A new substrate may cause a decrease of the activation time and an improvement of catalytic performance [13]. Therefore the investigation of the nature of the surface layer and its interaction with deeper layers are extremely important. As it was demonstrated by our previous in situ XAS studies, the VPO surface electronic structure is very sensitive to the reaction conditions $[14,15]$. In this work we report the first observation of the active VPO catalyst surface by XPS under reaction conditions.

\section{Experimental}

\subsection{Sample preparation and characterization}

Two VPO samples (called $\mathrm{VPO}_{\mathrm{P} 4}$ and $\mathrm{VPO}_{\mathrm{P} 9}$ in the following) were prepared and characterized as described in detail in [16]. (The sample annotation is the same as in Ref [16]) The precursor for $\mathrm{VPO}_{\mathrm{P} 9}$ was prepared from $\mathrm{V}_{2} \mathrm{O}_{4}$, $\mathrm{H}_{3} \mathrm{PO}_{4}$ and water. The mixture was heated in an autoclave $\left(145^{\circ} \mathrm{C}, 72 \mathrm{~h}\right)$, then washed with cold water and dried in air $\left(120^{\circ} \mathrm{C}, 16 \mathrm{~h}\right)$. The $\mathrm{VPO}_{\mathrm{P} 4}$ precursor was prepared using $\mathrm{V}_{2} \mathrm{O}_{5}, \mathrm{H}_{4} \mathrm{P}_{2} \mathrm{O}_{7}, \mathrm{H}_{3} \mathrm{PO}_{3}$ and water in the same way like $\mathrm{VPO}_{\mathrm{P} 9}$, with a subsequent reflux in water for $2 \mathrm{~h}$. The activation was performed in a laboratory microreactor in a mixture of $1.7 \% \mathrm{n}$-butane in air at $400^{\circ} \mathrm{C}$.

For the in situ XPS measurements the catalyst powder $(50 \mathrm{mg})$ after the test of catalytic performance was pressed into pellets with a diameter of $13 \mathrm{~mm}$, using a pressure of $10 \mathrm{MPa}$. During the XPS experiments the catalytic activity of the samples towards MA was measured using
Proton Transfer Reaction Mass Spectrometry (PTRMS) at outlet of the gas flow through the experimental chamber.

\subsection{Experimental conditions}

The samples were investigated in a constant gas flow. The mixture of $1.5 \% n$-butane in He (partial pressure 1.6 mbar) and oxygen (partial pressure 0.4 mbar) had a total pressure of 2 mbar in the reaction cell. Spectroscopic measurements were done at temperatures of $150-200^{\circ} \mathrm{C}$, where the MA yield was negligible, and at $400^{\circ} \mathrm{C}$, which is the usual reaction temperature. Additionally the catalysts were reduced in the absence of oxygen (in 1.6 mbar of $1.5 \% \mathrm{n}$-butane in $\mathrm{He}$ ) at $400^{\circ} \mathrm{C}$.

\subsection{In situ XPS}

The experiments were performed at beamline U49/2PGM1 at the synchrotron source BESSY-II in Berlin [18]. The in situ XPS system is a modified standard XPS spectrometer [19]. Three differential pumping stages keep the hemispherical analyzer at high vacuum while the pressure in the sample cell is in the mbar range. The reaction cell is separated from the synchrotron beam line by a $100 \mathrm{~nm}$ thick $\mathrm{SiN}_{\mathrm{x}} \mathrm{X}$-ray window. The main limiting factor for the maximum pressure in the reaction chamber is the scattering of photoelectrons by gas molecules. The pressure limit in our experiments was estimated to be approximately 2 mbar for the reaction gas mixture. At this pressure it is still possible to get spectra with good signal to noise ratio. A discussion of the general principles of an in situ XPS system can be found in [20]. The overall spectral resolution of the system was evaluated from a measurement of the $\operatorname{Ar} 2 p_{3 / 2}$ gas phase peak and found to be better than $0.3 \mathrm{eV}$ at a photon energy of $700 \mathrm{eV}$. We have recorded the $\mathrm{O} 1 \mathrm{~s} / \mathrm{V} 2 \mathrm{p}, \mathrm{C} 1 \mathrm{~s}$, $\mathrm{P} 2 \mathrm{p}$ and valence band regions in our experiments. The inci-

Table 1

\begin{tabular}{|c|c|c|c|}
\hline \multirow{2}{*}{$\begin{array}{c}\text { Photoelectron } \\
\text { kinetic energy, }\end{array}$} & \multicolumn{2}{|c|}{ Excitation } & Information \\
eV & $\begin{array}{c}\text { O1s- } \\
\text { depth [20], }\end{array}$ & P2p & nm. \\
\cline { 2 - 3 } & 730 & 335 & 1 \\
\hline 200 & $1254^{*}$ & 854 & 3 \\
\hline 720 & & & \\
\hline
\end{tabular}

* The $1254 \mathrm{eV}$ photon energy corresponds to $\mathrm{MgK}_{\mathrm{a}}$ line, which is in common use in laboratory XPS systems for chemical analysis (ESCA). 
a.

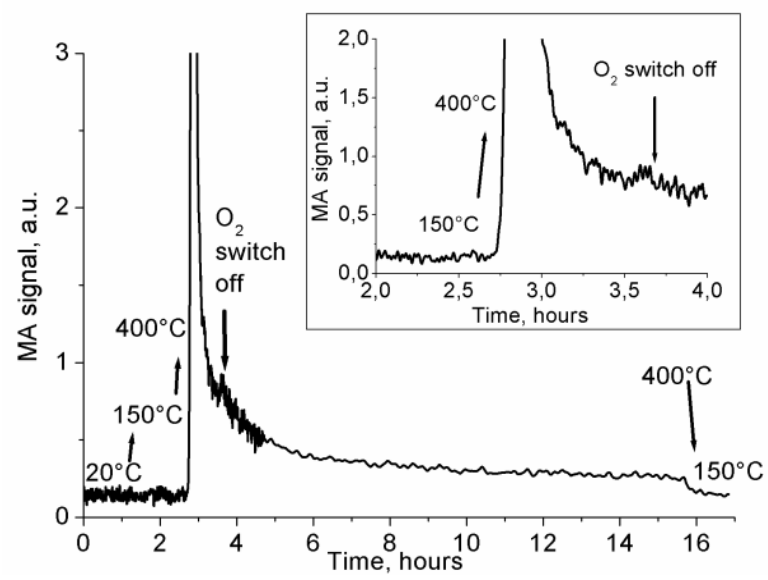

c.

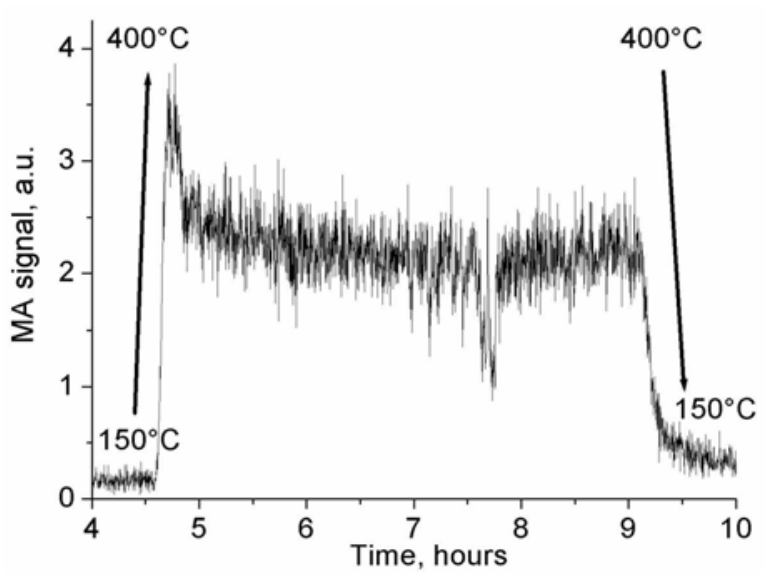

b.

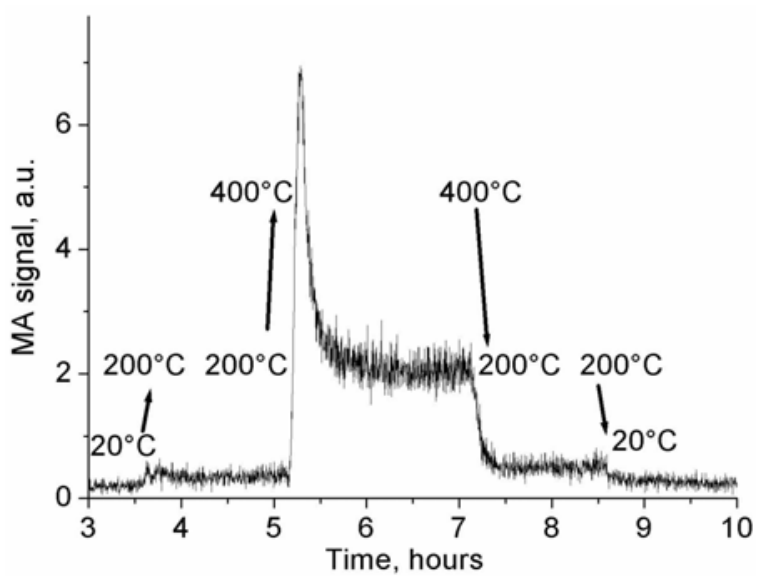

d.

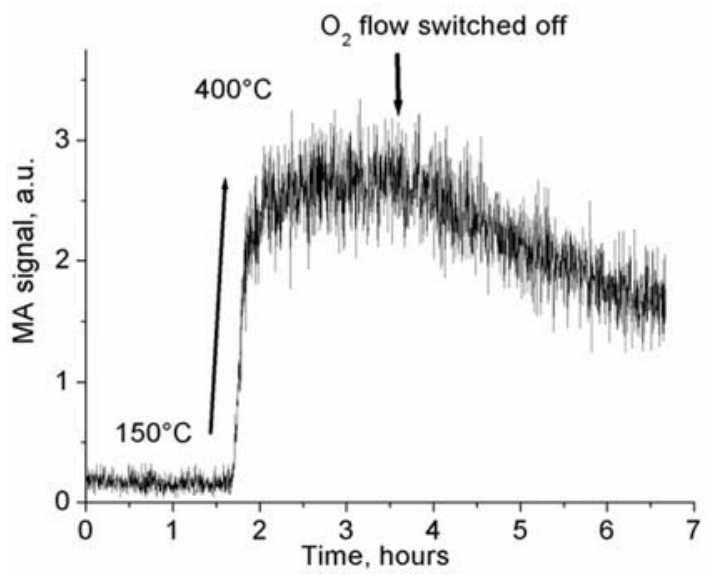

Figure 1: Catalytic reactivity towards MA registered by PTRMS (signal on $\mathrm{m} / \mathrm{e}=99 \mathrm{amu} / \mathrm{e}$ ). a) $\mathrm{VPO}_{\mathrm{P} 9}$ in reaction mixture and in $n$-butane/He atmosphere, b) $\mathrm{VPO}_{\mathrm{P} 4}$ in reaction mixture- first heating, c) second heating, d) third heating and in $n$-butane/He atmosphere

dent photon energy was varied such that the kinetic energy of the photoelectrons was constant for all recorded XPS regions, thus providing for a uniform information depth, a constant analyzer transmission function contribution as well as a constant gas phase scattering contribution. In addition we have performed depth-profiling by varying the excitation photon energy applied to the same core-level, which leads to a change of the photoelectron kinetic energy, and as a consequence to a change in the information depth. The values for the excitation energies and corresponding information depths taken from the "universal curve" [21] are presented in table 1.

\section{Results and discussion}

\subsection{Sample activity during spectroscopic meas- urements}

The catalytic reactivity (Fig.1) was measured using PTRMS. Protonated MA molecules produce a signal at $\mathrm{m} / \mathrm{e}=99 \mathrm{amu} / \mathrm{e}$. The mass spectra were recorded simultaneously with the XPS measurements, which allowed us to correlate the XPS results with the catalytic activity of the material. No significant increase in the MA signal was observed after heating the samples to 150 or $200^{\circ} \mathrm{C}$ (Fig.1a.-b.). Therefore, the samples can be considered as practically inactive under these conditions. The XPS measurements of the inactive surface were performed at 150$200^{\circ} \mathrm{C}$ (and not at room temperature) because it was found that at $200^{\circ} \mathrm{C}$ differential charging effects are reduced [14].

When the samples were heated to $400^{\circ} \mathrm{C}$ with $20^{\circ} \mathrm{C} /$ min heating ramp (Fig $1 \mathrm{a}, \mathrm{b}$ ), a peak in the MA signal followed by a decrease to a constant MA signal level after 
less than one hour was observed. It can be clearly seen that MA could be detected for both catalysts at $400^{\circ} \mathrm{C}$ and practically no MA was detectable after cooling down to temperatures lower than $200^{\circ} \mathrm{C}$. The temperature was cycled 3 times between $150-200^{\circ} \mathrm{C}$ and $400^{\circ} \mathrm{C}$ for the $\mathrm{VPO}_{\mathrm{P} 4}$ sample (see Fig.1 b-d). The steady-state level of the MA yield at $400^{\circ} \mathrm{C}$ was found to be the same in all three cycles, which indicates that the MA is a product of the catalytic process and not an artefact from an unsteady-state process. The amplitude of the initial peak of the PTRMS MA signal significantly decreased during the second heating cycle (see Fig. 1b), and no peak was visible during the third cycle (Fig. 1c). The behaviour of this peak clearly shows that it is caused by the desorption of MA that was produced in the prior activation of the catalyst in a microreactor, before our XPS experiments. The same behaviour was observed in our previous experiments [14]. The absence of the desorption peak during the third heating cycle does not indicate the absence of adsorbed MA molecules but rather the lack of sensitivity of our system to register the desorption of the small amount of MA attached to the surface at the lowpressure conditions. The observed steady-state MA yield in the reaction gas mixture at $400^{\circ} \mathrm{C}$ was 2.6 times higher for $\mathrm{VPO}_{\mathrm{P} 4}$ compared to $\mathrm{VPO}_{\mathrm{P} 9}$. After normalisation to the BET surface area $\left(23\right.$ and $11 \mathrm{~m}^{2} \mathrm{~g}^{-1}$ for $\mathrm{VPO}_{\mathrm{P} 4}$ and $\mathrm{VPO}_{\mathrm{P} 9}$, respectively) the ratio of the normalized yields is 1.2 , which indicates that both samples have nearly the same intrinsic activity to MA. The reduction of the samples in a $n$ butane/He atmosphere (see Figs. 1 a,d) led to a significantly different deactivation time behaviour. A fit of the MA yield versus time in n-butane/He with a first order exponential decay function gave time constants of 6.4 and $0.9 \mathrm{~h}$ for $\mathrm{VPO}_{\mathrm{P} 4}$ and $\mathrm{VPO}_{\mathrm{P} 9}$, respectively. Such a different response on reducing conditions can mean a different composition of a bulk material of the catalysts while the same intrinsic activity suggests the same nature of active surface. This hypothesis will be supported below by spectroscopic data.

\subsection{XPS data}

The V2 $p_{3 / 2}$ XPS peak was used to follow the changes in the vanadium oxidation state under the different experimental conditions. A Shirley-type background was subtracted. The energy scale was calibrated by assuming a BE of $530 \mathrm{eV}$ for the $\mathrm{O} 1 \mathrm{~s}$ peak, which is the value found in the literature for vanadium oxides [21]. At room temperature a strong distortion of the peak shape was found due to differential charging. To minimize the charging effect we increased the sample temperature to $150-200^{\circ} \mathrm{C}$ as was discussed before.

Fig. 2 shows $\mathrm{V} 2 \mathrm{p}_{3 / 2}$ spectra of sample $\mathrm{VPO}_{\mathrm{P} 4}$ for two different incident photon energies: $860 \mathrm{eV}$ (top) with an information depth of about $1 \mathrm{~nm}$, and $1254 \mathrm{eV}$ (bottom) with an information depth of about $3 \mathrm{~nm}$ (We will in the following refer to the $860 \mathrm{eV}$ spectra as "surface", and the $1254 \mathrm{eV}$ spectra as "bulk" spectra). In each case V2 $p_{3 / 2}$

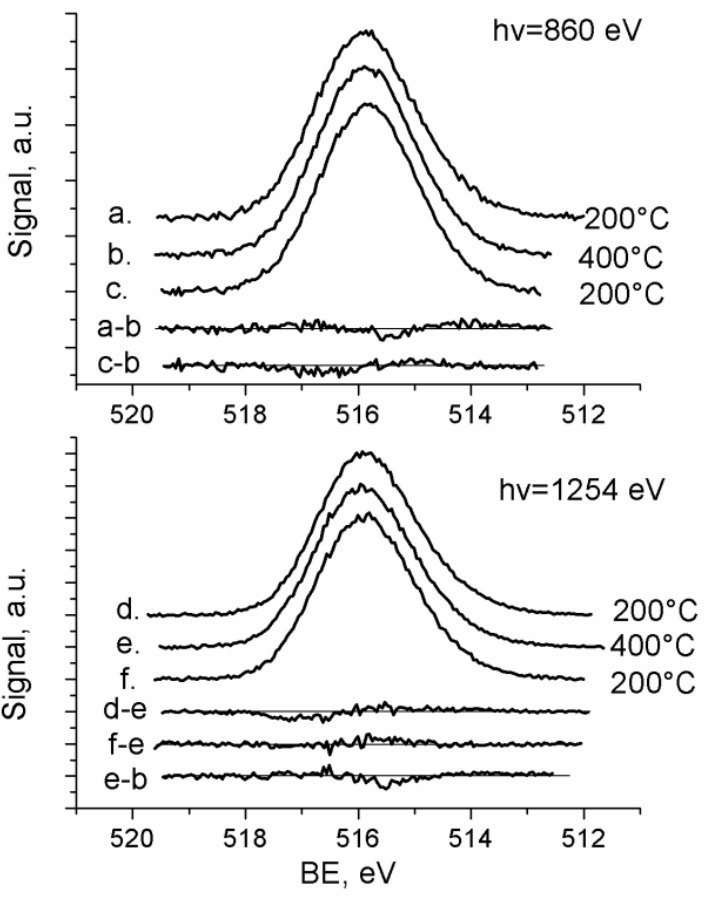

Figure 2: $\mathrm{V} 2 \mathrm{p}_{3 / 2}$ spectra of $\mathrm{VPO}_{\mathrm{P} 4}$ in heating-cooling experiment. a-c) hv $=860 \mathrm{eV}, \mathrm{d}-\mathrm{f}$ ) $\mathrm{hv}=1254 \mathrm{eV}$

spectra were taken at $200^{\circ} \mathrm{C}$, then at $400^{\circ} \mathrm{C}$, and at the end of the experiment again at $200^{\circ} \mathrm{C}$ in the reaction mixture. Fig. 2 shows also the difference spectra between the $400^{\circ} \mathrm{C}$ and $200^{\circ} \mathrm{C}$ data for each incident photon energy. One has to be careful when evaluating the difference spectra, since they are influenced by such factors as charging effects and BE shifts [22]. They are, however, useful to get an impression about qualitative changes in the spectra. The difference spectra in Fig. 2 show only small features with amplitudes on the order of the noise level, which implies that within the uncertainty of our experiments no changes are observed in the spectra. This leads us to the conclusions that the vanadium oxidation state in the $\mathrm{VPO}_{\mathrm{P} 4}$ sample is uniform with depth and does not change with temperature.

For the $\mathrm{VPO}_{\mathrm{P} 9}$ sample a different behaviour was observed. Fig. 3 shows $\mathrm{V} 2 \mathrm{p}_{3 / 2}$ spectra of $\mathrm{VPO}_{\mathrm{P} 9}$ with the more surface-sensitive spectra displayed in the top part of the figure and the more bulk sensitive spectra in the bottom part. Sample VPO $\mathrm{PP}_{\mathrm{P}}$ shows strong changes of the vanadium oxidation state with temperature. A peak at $517 \mathrm{eV}$ is clearly visible in the $400^{\circ} \mathrm{C}-150^{\circ} \mathrm{C}$ difference spectra for both bulk and surface sensitive measurements. This peak has a $\mathrm{BE}$ difference of about $-13 \mathrm{eV}$ relative to $\mathrm{O} 1 \mathrm{~s}$, which is a typical value for $\mathrm{V}^{5+}$ species [23].

Fig. 4 shows a comparison of the spectra taken under reaction conditions $\left(400^{\circ} \mathrm{C}\right)$ for the two different samples. Also shown in Fig. 4 are the differences between the bulk spectra and the surface spectra of the two samples. It is obvious from a comparison of the spectra of the two catalysts at $400^{\circ} \mathrm{C}$ in the reaction mixture that the oxidation state of the surface is more similar than that of the bulk . 

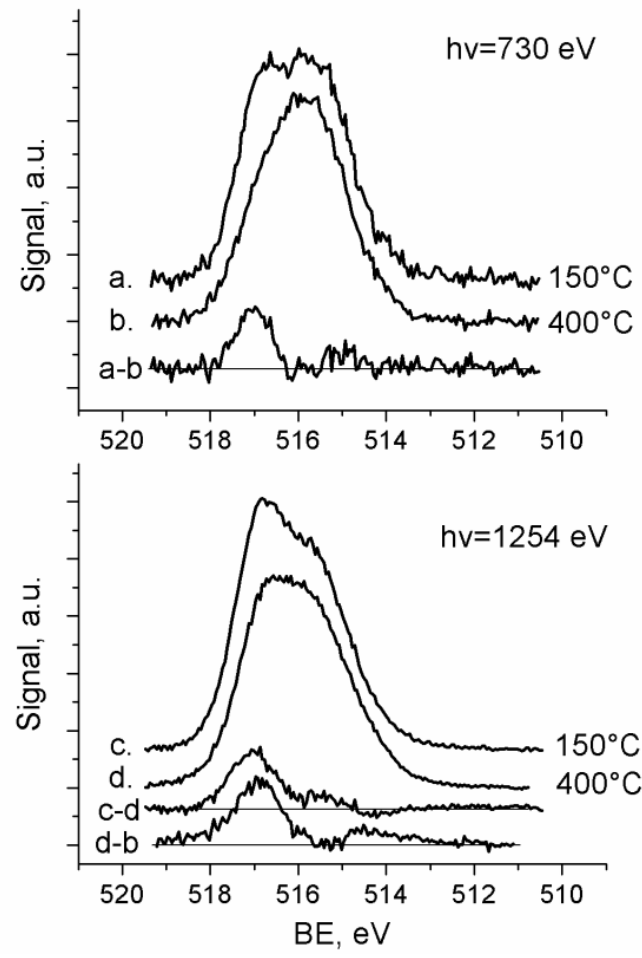

Figure 3: $\mathrm{V} 2 \mathrm{p}_{3 / 2}$ spectra of $\mathrm{VPO}_{\mathrm{P} 9}$ before and after heating in reaction mixture. a-b) $h v=730 \mathrm{eV}, \mathrm{c}-\mathrm{d}) \mathrm{hv}=1254 \mathrm{eV}$

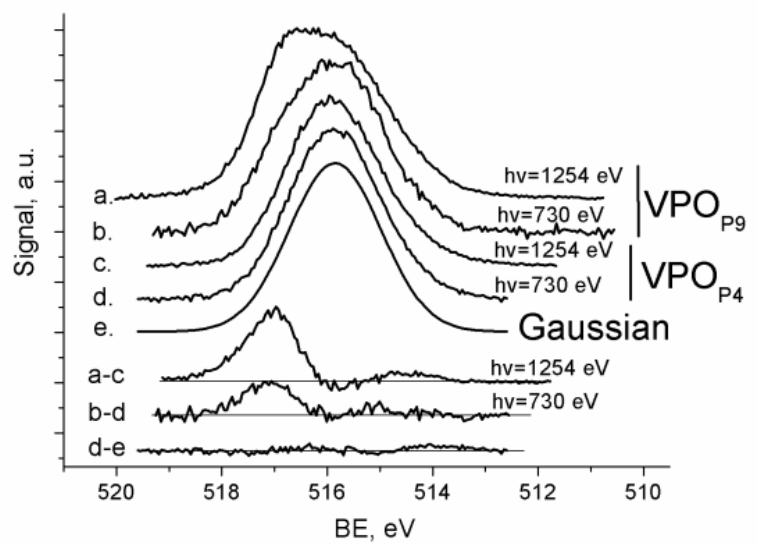

Figure 4: Comparison of $\mathrm{V} 2_{3 / 2}$ peaks of $\mathrm{VPO}_{\mathrm{P} 4}$ and $\mathrm{VPO}_{\mathrm{P} 9}$ at reaction conditions. a-b) $\left.\left.\mathrm{VPO}_{\mathrm{P} 9}, \mathrm{c}-\mathrm{d}\right) \mathrm{VPO}_{\mathrm{P} 4}, \mathrm{e}\right)$ Gaussian

The exact determination of the oxidation state is quite complicated. The usual approach to fit a spectrum with several peaks [24], each representing a unique oxidation state, is based on the knowledge of the line shape and the BE position of the peaks for each oxidation state, which is often difficult to determine experimentally. A wide range of $\mathrm{V} 2 \mathrm{p}_{3 / 2}$ BEs for VPO is reported in the literature (see Table 1 in Ref. [25]), which makes this fit procedure complicated. Another method to determine the oxidation state was suggested by Coulston et al. [26] This procedure is based on the $\mathrm{BE}$ difference between the first momenta of the $\mathrm{O} 1 \mathrm{~s}$ and $\mathrm{V} 2 \mathrm{p}_{3 / 2}$ peaks. However, the authors mentioned that the results depend on the presence of adsorbates, which distort the overall $\mathrm{O} 1 \mathrm{~s}$ peak shape.

The shape of the surface $\mathrm{V} 2 \mathrm{p}_{3 / 2}$ peak of $\mathrm{VPO}_{\mathrm{P} 4}$, (spectrum d in Fig. 4) under reaction conditions can be fit with a single Gaussian. We can therefore conclude that the surface of $\mathrm{VPO}_{\mathrm{P} 4}$ has an oxidation state equal to 4 within the error of our measurement. A small amount of $\mathrm{V}^{5+}$ is present in the $\mathrm{VPO}_{\mathrm{P} 9}$ surface spectrum. This $\mathrm{V}^{5+}$ species can be related to deeper layers below the surface, since photoelectrons escape from an infinite range of depth with exponentially decreasing probability and therefore the information depth value represents only a mean free path of photoelectrons. Thus it can be deduced that a surface layer with a thickness of about $1 \mathrm{~nm}$ for both catalysts has the same oxidation state at the reaction conditions. Taking into account nearly the same intrinsic catalytic performance of the catalysts this leads us to the conclusion that only this layer participates directly in the catalytic cycle while deeper layers (which show quite different XPS spectra for the two samples) act only as a substrate. This conclusion is in agreement with literature data [7,10-12], which suggest that the active surface layer has a different composition than the bulk.

The stability of the active layer was investigated by reducing it in an $n$-butane/He atmosphere. It is clearly visible in Fig. 5 that the $\mathrm{VPO}_{\mathrm{P} 9}$ surface responds much more dynamically to the reducing conditions compared to $\mathrm{VPO}_{\mathrm{P} 4}$. The MA yield for $\mathrm{VPO}_{\mathrm{P} 9}$ also decreases much faster (see Fig. 1 a,d). There could be two reasons for the different response of the two samples to the changing conditions: either differences in the properties of the active layer, or a different interaction with deeper layers (substrate). The latter one is more probable since the oxidation state of the two surfaces was the same for both catalysts under reaction conditions, which suggests the same nature of the surface layer for both catalysts. This implies that the oxygen transport from the substrate to the surface is higher for $\mathrm{VPO}_{\mathrm{P} 4}$ compared to $\mathrm{VPO}_{\mathrm{P} 9}$. This obviously does not influence significantly the catalytic performance of the active layer in co-feed of oxygen and n-butane, but apparently makes sample $\mathrm{VPO}_{\mathrm{P} 4}$ more stable with respect to conditions changes.

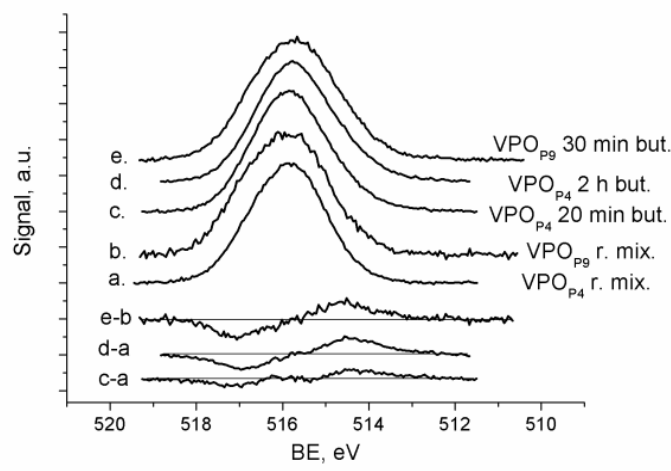

Figure 5: Changes of surface $V 2 p_{3 / 2}$ spectra in $n$-butane at $400^{\circ} \mathrm{C}$. a) $\mathrm{VPO}_{\mathrm{P} 4}$ in reaction mixture, b) $\mathrm{VPO}_{\mathrm{P} 9}$ in reaction mixture, c) $\mathrm{VPO}_{\mathrm{P} 4}$ after $20 \mathrm{~min}$ in $n$-butane, d) $\mathrm{VPO}_{\mathrm{P} 4}$ after 2 hours in $n$-butane, e) $\mathrm{VPO}_{\mathrm{P} 9}$ after $30 \mathrm{~min}$ in $n$-butane 


\section{3. $P / V$ ratios}

The $\mathrm{P} / \mathrm{V}$ ratio is often considered an important factor for the catalytic properties of VPO [27]. This argument is based mainly on XPS experiments where a phosphorous enrichment at the surface was found. As was reported in [26] the absolute $\mathrm{P} / \mathrm{V}$ ratio value depends strongly on the assumptions made about the sensitivity factors. The most widely used theoretically calculated photoionisation crosssections $[28,29]$ lead to higher $\mathrm{P} / \mathrm{V}$ ratios than estimated from measurements of reference compounds with known $\mathrm{P} / \mathrm{V}$ ratio [26]. We have also performed measurements on some reference compounds, namely $\alpha-, \delta$-, and $\gamma-\mathrm{VOPO}_{4}$. Our measurements yielded sensitivity factors that are about 0.5 times that from theoretical calculations [29], in agreement with other experimental measurements where the same factor between measured and calculated values was found [26]. On the base of the experimental data we have calculated the $\mathrm{P} / \mathrm{V}$ ratios for all the conditions we used for our catalysts. The ratios did not show any correlation with the experimental conditions, but are rather randomly distributed within a variation of $\pm 10 \%$ range of the total value. These variations are comparable to the background subtraction error, which was estimated to be $\pm 10 \%$. The average $\mathrm{P} / \mathrm{V}$ ratio for $\mathrm{VPO}_{\mathrm{P} 4}$ is 1.3 for the surface and 1.2 for the deeper layers, i.e. there is no difference within the experimental error. The values are different from unity, which should be the case according to the preparation. The deviation may be related to an error of the experimental estimation of the absolute value of the sensitivity factors.

\section{References}

[1] V.V. Guliants, J.B. Benziger, S. Sundaresan, I.E. Wachs, J.M. Jehng, J.E. Roberts, Catalysis Today 28 (1996) 275-295

[2] V.V. Guliants, S.A. Holmes, J.B. Benziger, P. Heaney, D. Yates, I.E. Wachs, J.Mol.Cat. A 172 (2001) 265-276

[3] T. Shimoda, T. Okuhara, M. Misono, Bull. Chem. Soc. Jpn., 58 (1985) 2163-2171

[4] J.C. Volta, K. Bere, Y.J. Zhang, R. Oliver, ACS Symposium Series 523 (1993) 217-230

[5] J.-C. Volta, Catalysis Today 32 (1996) 29-36

[6] K. Ait-Lachgar, M Abon, J.C. Volta, Journal of Catalysis 171 (1997) 383-390

[7] G.J. Hutchings, C.J. Kiely, M.T. Sananes-Schulz, A. Burrows, J.C. Volta, Cat. Today 40 (1998) 273-286

[8] G.W. Coulston, S.R. Bare, H. Kung, K. Birkeland, G.K. Bethke, R. Harlow, N. Herron, P.L. Lee, Science 275 (1997) 191-193

[9] M.Abon, K.E. Bere, P.Delichere, Catalysis Today 33 (1997) $15-23$

[10] H. Bluhm, M. Hävecker, E. Kleimenov, A. Knop-Gericke, A. Liskowski, R. Schlögl, D. S. Su, Topics in Catalysis 23 (2003) 99-107

[11] M. Ruitenbeek, A.J. van Dillen, A. Barbon, E.E. van Faassen, D.C. Koningsberger, J.W. Geus, Cat. Letters 55 (1998) 133139

[12] G.J. Hutchings, J.A. Lopez-Sanchez, J.K. Bartley, J.M. Webster, A. Burrows, C.J. Kiely, A.F. Carley, C. Rhodes, M.

\section{Conclusions}

We investigated two VPO catalysts with nearly the same intrinsic catalytic activities. One catalyst showed a high homogeneity depending on depth and stability of oxidation state towards condition changes. Another catalyst had a gradient of oxidation state and showed flexibility of oxidation state with conditions changes. At the reaction conditions both catalysts had the same surface oxidation state, which was close to 4 , while the bulk oxidation state differed significantly. The experimental results suggest that in VPO the catalytically active species located in the topmost surface layers (up to $1 \mathrm{~nm}$ depth) are different from the bulk structure. The deeper layers are acting as a substrate material only. The finding indicates that the bulk oxidation state in this case has no direct correlation to the catalytic properties. The concept of a difference in a structure of the active layer and of the bulk can play a central role in the strategy of improvement of a VPO catalyst. While the modern preparation methods are designed to get $(\mathrm{VO})_{2} \mathrm{P}_{2} \mathrm{O}_{7}$ bulk phase, the optimization of an active surface layer formation could be more important.

\section{Acknowledgement}

We would like to thank BESSY staff for the support of our experiments.
Havecker, A. Knop-Gericke, R.W. Mayer, R. Schlogl, J.C. Volta, M. Poliakoff, J.Catal. 208 (2002) 197-210

[13] M.J. Ledoux, C. Crouzet, C. Pham-Huu, V. Turines, K. Kourtakis, P.L. Mills, J.J. Lerou, J. Catal. 203 (2001) 495-508

[14] M. Hävecker, R. W. Mayer, A. Knop-Gericke, H. Bluhm, E. Kleimenov, A. Liskowski, D. Su, R. Follath, F. G. Requejo, D. F. Ogletree, M. Salemon, J. A. Lopez-Sanchez, J. K. Bartley, G. J. Hutchings, R. Schlögl, J. Phys. Chem. B 107 (2003) 4587-4596

[15] M Hävecker, A. Knop-Gericke, H. Bluhm, E. Kleimenov, R.W.Mayer, M.Fait, R. Schlögl, Appl. Surf. Sci. 230 (2004) 272-282

[16] J.A. Lopez-Sanchez, L. Griesel, J. Bartley, R. Wells, A. Liskowski, D. Su, R. Shlögl, J.-C. Volta, G. Hutchings, PCCP 5 (2003) 3525-3533

[17] F. Senf, F. Eggenstein, U. Flechsig, R. Follath, S. Hartlaub, H. Lammert, T. Noll, J. S. Schmidt, G. Reichardt, O. Schwarzkopf, M. Weiss, T. Zeschke and W. Gudat, Nucl. Instr. Meth. A 467-468 (2001) 474-478

[18] Phoibos 150 hemispherical analyzer, manufactured by Specs $\mathrm{GmbH}$, Berlin.

[19] D.F. Ogletree, H. Bluhm, G. Lebedev, C.S. Fadley, Z. Hussain, M. Salemon, Rev. Sci. Instrum. 73 (2002) 3872-3877

[20] M. P.Seah, Surf. Interface Anal. 9 (1986) 85-98

[21] Ed. J. Chastain, Handbook of X-ray photoelectron spectroscopy (1992)

[22] A. Proctor, P.M.A. Sherwood, Anal. Chem. 54 (1982) 13-19 
[23] J.Mendialdua, R.Casanova, Y.Barbaux, J. Electr. Sp. Rel. Ph. 71 (1995) 249-261

[24] Ed. D. Briggs, M.P. Seah, Practical surface analysis, Second edition (1990), vol.1, p. 572

[25] L.M.Cornaglia, E.A.Lombardo, Applied Catalysis A 127 (1995) 125-138
[26] G. Coulston, E. A. Thompson, N. Herron, J. Catal. 163 (1996) 122-129

[27] J.-C. Volta, Chemistry 3 (2000) 717-723

[28] J. Scofield, J.Elect.Spec.Rel.Phen. 8 (1976) 129-137

[29] J. Yeh. I. Lindau, At.Dat.Nucl.Dat.Tabl. 32 (1985) 1-155 